\title{
From the Editor-in-Chief
}

\author{
Kimon P. Valavanis
}

Published online: 7 November 2009

(C) Springer Science + Business Media B.V. 2009

\section{Dear Colleagues,}

This academic year is over or almost over. As we all start making our plans for the summer and the 2010-11 academic year, we should think of JINT, too. By that I mean, explore ways to make the difference compared to similar journals in the field. Allow me to take this opportunity and pose a few questions:

1. Does JINT serve its purpose?

2. Does JINT serve its authors and readership?

3. Is JINT making contributions to the advancement of science and engineering in robotics, automation and unmanned systems?

4. What is unique, if anything, about JINT?

5. What needs be improved?

6. How would you like JINT to 'reshape' if you were to start today?

I think all of the above are valid points and concerns; certainly I worry all the time about what to do next, so I encourage you to take the time and tell me, send me an e-mail with your recommendations.

We have shown growth, we have had higher/improved impact factors for three consecutive years, we march along.

Enjoy the issue,

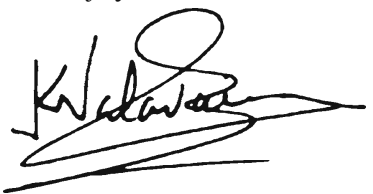

Kimon P. Valavanis

Editor-in-Chief

K. P. Valavanis $(\varangle)$

Journal of Intelligent and Robotic Systems,

Department of Electrical and Computer Engineering,

School of Engineering and Computer Science,

University of Denver, Denver, CO 80208, USA

e-mail:kvalavan@du.edu 